Issn: 1808 - 799X

ano 10, no 14 - 2012

\title{
A TELENOVELA “GLOBAL” E A DEFESA DO EMPRESARIAMENTO DO ENSINO PELA BURGUESIA DO SETOR DE COMUNICAÇÕES
}

Renata Maldonado ${ }^{1}$

\section{Resumo:}

Este artigo tem o objetivo de discutir a importância da dramaturgia televisiva enquanto um espaço de legitimação do projeto político- pedagógico dos empresários do setor de comunicações no Brasil. Busca-se abordar esta questão a partir da análise de duas telenovelas veiculadas pela Rede Globo de Televisão no ano de 2007, que contemplaram a temática educacional: Sete Pecados e Duas Caras. Utiliza-se como referencial teórico os pressupostos do materialismo histórico, destacando-se a obra de autores que analisaram a vinculação entre marxismo e literatura, tais como Georg Lukács e Fredric Jameson. Pretende-se, portanto, articular o discurso televisivo sobre a educação com as estratégias de imposição e disseminação do projeto pedagógico empresarial brasileiro, no qual a Rede Globo ocupa uma posição de destaque.

Palavras-chave: televisão, empresariado, educação

\begin{abstract}
This paper aims to discuss the importance of television drama as a space of legitimation of the political-pedagogical project of the entrepreneurs of the communication industry in Brazil. It attempts to address the issue form the analysis of two soap operas broadcast b Globo Television Network in 2007, wich contemplated the theme of education: Sete Pecados and Duas Caras. It is used as theoretical assumptions of historical materialism, highlighting the work of authors who have examined the link between marxism and literature, such as Georg Lukács and Fredric Jameson. It is intended, therefore, articulate the television speech on education with the strategies of enforcement and dissemination of the brazilian business pedagogical project, in wich Globo network occupies a prominent position.
\end{abstract}

Key-words: television; entrepreneurs; education

\footnotetext{
${ }^{1}$ Doutora em Educação pela Universidade Federal Fluminense. Professora da Universidade Estadual do Rio de Janeiro - Faculdade de Educação da Baixada Fluminense. E-mail: r.maldonado@globo.com
} 
Este artigo tem o propósito de analisar a produção social da educação pela Rede Globo de Televisão ${ }^{2}$, através da análise de seu programa de maior relevância social, as telenovelas. Busca-se apreender, portanto, como o maior sistema de comunicação do Brasil, o Sistema Globo, concebe e representa a educação no seu principal canal de entretenimento popular, a Rede Globo de Televisão. Com este objetivo, serão analisadas as concepções de educação veiculadas através do discurso televisivo na novela "Duas Caras", transmitida pela emissora no ano de 2007 e sua articulação ao projeto educacional da burguesia do setor de comunicações e às distintas frações da classe empresarial. Destacase, ainda, a vinculação da proposta pedagógica destes diferentes segmentos de classe às reformas que vem sendo implantadas pelo Estado brasileiro no âmbito do ensino superior.

Parte-se do princípio de a produção social do discurso sobre educação proposto pelos empresários do setor de comunicação atua prioritariamente através da inserção da sua proposta educacional na programação televisiva, dos quais se destacam as emissões de maior audiência, como as telenovelas.

Embora não se possa dizer que o empresariado do setor de comunicações seja numericamente expressivo, em função da grande concentração desta área no país e da centralidade da indústria cultural no capitalismo tardio, esta desempenha um papel social estratégico. Além de serem responsáveis na transmissão e fixação de valores, signos e padrões de consumo, os meios de comunicação têm fundamental importância na organização das relações de poder contemporâneas. Em função da sua disseminação massiva nas últimas décadas, pode-se dizer que, no Brasil, a televisão é mídia de maior relevância social, definindo padrões de comportamentos e modos de pensar de grande parte da sociedade.

No Brasil, o mercado brasileiro de televisão constituiu-se em um oligopólio, formado, prioritariamente por seis grandes redes privadas nacionais: Globo; Record; SBT; Rede TV!; Bandeirantes e CNT. O caráter centralizador deste mercado gera, portanto, um intenso fortalecimento desses grupos políticos, que, utilizando deste poder de barganha, impõem condições ao governo, em troca de

\footnotetext{
${ }^{2}$ Este artigo faz parte da minha tese de dotourado defendida no Programa de Pós-Graduação na Universidade Federal Fluminense, em 2010, orientada pelo prof. Dr. Ronaldo Rosas Reis e subvencionada pela CAPES.
} 
apoio político. Este último, consciente da visibilidade que a indústria cultural adquiriu nesta nova fase do capitalismo, promove amplas concessões às empresas de comunicações. Embora em última instância o capital seja o veículo motor da indústria cultural, Bolaño atenta para a existência de três sujeitos distintos que seriam os eixos centrais desse modo de regulação, que contemplam interesses "diferentes e assimétricos. Ao capital interessa o dinheiro; ao Estado, o poder; e ao público, diversão no sentido de Brecht, a função natural da arte" (2005, p. 20).

Nas últimas décadas, como já se mencionou anteriormente, a Rede Globo de Televisão vem sendo amplamente beneficiada pelas relações estreitas firmadas com os sucessivos governos Em virtude do grande capital simbólico ${ }^{3}$ conquistado desde os governos militares, a atuação desta empresa no cenário nacional é de importância estratégica para a tomada de grande parte das mais importantes decisões políticas do país. Segundo Charão \& Biondi (2008), as Organizações Globo ocupariam o 36이 lugar no ranking dos grupos empresariais mais importantes do país. A conquista de maior parte da audiência em quase todo o território nacional, somado ao poder político que a empresa adquiriu nos últimos anos, possibilitou que esta seja um ator decisivo na disseminação de crenças e valores, em sua maioria, produzidos pelas classes dominantes para grande maioria da população do país.

Nesse contexto, o discurso da emissora sobre a realidade educacional do país vem sendo tema recorrente ao longo da programação da emissora nos últimos quarenta anos. Além da elaboração dos chamados programas educativos, Castro (2005) assinala a presença da categoria educação em gêneros distintos, tais como programas infantis ou voltados para o ensino profissionalizante, como o "Novo Telecurso". No entanto, a mesma autora afirma que a produção e veiculação de diferentes programas que abordam a questão educacional se inserem como estratégia da Rede Globo em lançar e publicizar produtos e serviços lucrativos às Organizações Globo, e, principalmente à Fundação Roberto Marinho. No entanto, percebe-se que a teledramaturgia também vem sendo

\footnotetext{
${ }^{3}$ Refiro-me aqui ao conceito de capital simbólico proposto por Pierre Bourdieu (2003), refere-se a mecanismos de distinção que determinados sujeitos dispõem em certas áreas do conhecimento. Este é reforçado, em geral, pelo uso de signos que atuam como elemento de distinção e possibilitam que os detentores de maior capital simbólico atuem como agentes opressores dos que são desprovidos deste. Em geral, o detentor de maior capital simbólico, relaciona-se aos indivíduos que dispõem de maior poder econômico na estrutura social. Cf.BOURDIEU, 2003.
} 
utilizada como um espaço publicitário que visa disseminar as concepções de educação defendidas pela empresa e seus "parceiros" neste âmbito.

Embora a inserção da temática educacional na teledramaturgia da Rede Globo venha ocorrendo esporadicamente desde o início da década de 1970, a partir de 2007 houve um significativo aumento de interesse da emissora por temas educacionais, que ocupou o centro de duas telenovelas consecutivamente veiculadas no horário nobre: "Sete Pecados" (2007) e "Duas Caras" (2007). Neste artigo, analisar-se-á a segunda novela, considerando que esta abordou diretamente alguns aspectos do projeto educacional que vêm sendo implantado pelo Estado neoliberal nos últimos anos: a expansão do processo de privatização do ensino superior.

Pode-se dizer, portanto, que nos últimos anos as Organizações Globo, através de seu principal canal de entretenimento popular, a Rede Globo de Televisão, vêm utilizando a teledramaturgia para veicular e estabelecer o consenso social em torno das posições pedagógicas defendidas pelas diferentes frações da burguesia brasileira. Isto é, além dos produtos educacionais gerados e difundidos pela Fundação Roberto Marinho e pelo conglomerado das empresas que compõem as Organizações Globo, as telenovelas têm por objetivos principais ampliar o raio de alcance das ideias educacionais da classe dominante brasileira e, não menos importante, consolidar a posição hegemônica da Rede Globo de Televisão no cenário nacional.

Destaca-se, portanto, o papel da burguesia do setor de entretenimento e comunicação que, desde meados da década de 1990, vem disseminando nacionalmente o projeto político-pedagógico do empresariado brasileiro como um todo. Não constitui, portanto, exagero afirmar que as telenovelas produzidas e veiculadas pela principal emissora do país fazem parte da sua estratégia políticoideológica no sentido de alcançar tais objetivos. Dessa forma, com o objetivo de apreender a teleologia político-pedagógica que as telenovelas contêm, faz-se necessário a realização de uma análise do processo de construção do discurso das mesmas, acreditando-se que através do exame dos seus enunciados seja possível sublinhar o papel central da Rede Globo de Televisão num todo articulado pela convergência dos seus próprios interesses, dos interesses do empresariado brasileiro e dos interesses de segmentos liberais e conservadores da classe política que se fazem presentes no aparato do Estado. 


\section{EDUCAÇÃO, CULTURA E IDEOLOGIA}

Parte-se do pressuposto que o discurso transmitido através dos artefatos culturais televisivos comportaria elementos do projeto político-pedagógico que vem sendo implantado pelo Estado brasileiro nos âmbitos da educação básica e superior desde meados da década de 1990. Este discurso teria o propósito de disseminar as concepções educacionais preconizadas pela classe empresarial e que estão sendo implementadas pelo Estado brasileiro. Destaca-se aqui, a reforma do ensino superior que vem sendo realizada pelos últimos.

As concepções educacionais transmitidas através das telenovelas teriam o propósito de obter um consenso social acerca das políticas na área de educação que ainda não foram integralmente executadas pelo Estado brasileiro. Este processo ocorreria em função da natureza dos artefatos culturais que, mesmo em contexto de grande aproximação entre as esferas de natureza cultural e econômica ${ }^{4}$, como Jameson (2000) apontou em sua obra, estes ainda possuiriam uma relativa autonomia. $O$ processo artístico, segundo a perspectiva marxista, estaria dialeticamente inserido e seria determinado pelo modo de produção em vigor.

Embora o materialismo histórico conceba a infra-estrutura econômica como seu eixo norteador, os fenômenos de natureza ideológica o determinariam de modo secundário. Estes domínios, dos quais se inclui aqui a literatura, "sont les conséquences et les formes productives matérielles et de la lutte de classes "(Lukács, 1975, p.67). Simultaneamente, eles interagiriam com a base econômica que, em última instância, predominaria sobre todo o conjunto social. Marx \& Engels, portanto, consideraram que o desenvolvimento de campos específicos da atividade humana não poderia ser compreendido com base estritamente em suas conexões imanentes. Estas estão presentes, sem dúvida, na realidade objetiva, porém esta existência é momentânea no conjunto do desenvolvimento histórico. No interior deste, portanto, mediante um complexo

\footnotetext{
${ }^{4}$ De acordo com Jameson, uma das principais característicos do atual estágio do capitalismo, denominado tardio pelo autor, é a estreita aproximação dos campos da cultura e da economia. Ver: São Paulo: Editora Ática, 2000. Pós-modernismo: a lógica cultural do capitalismo tardio. $2^{\underline{a}}$ edição.
} 
conjunto de interações, o elemento principal é exercido pelo desenvolvimento das forças sociais produtivas. De acordo com Lukács (1965):

\begin{abstract}
"Portanto, a existência e a essência, a gênese e a eficácia da literatura só podem ser compreendidas e explicadas no quadro histórico geral de todo o sistema. A gênese e 0 desenvolvimento da literatura são parte do processo histórico geral da sociedade. A essência e o valor estético das obras literárias, bem como a influência exercida por elas, constituem parte daquele processo social geral e unitário através do qual o homem faz seu mundo pela própria consciência. Do primeiro ponto de vista, a estética marxista e a história marxista da literatura e da arte fazem parte do materialismo histórico, ao passo que, do segundo ponto de vista, a estética marxista é uma aplicação do materialismo dialético (sendo, em ambos os casos, uma parte peculiar, especial, do conjunto, com determinadas leis específicas, determinados princípios exclusivos: os princípios estéticos" (p.13).
\end{abstract}

É importante compreender que o posicionamento de Marx \& Engels acerca dos problemas literários se articula à luta dos autores contra a perversão burguesa sobre a consciência de classe proletária. Seu embate teórico era, sobretudo, contra autores tais como Heinrich Heine que defendiam uma estética idealista e acreditavam que a arte possuiria um significado autônomo, intrínseco. Esta estaria, portanto, além das lutas sociais e políticas. Nesse sentido, os autores marxistas chamaram a atenção para a existência única da ciência da história, no qual os problemas de natureza literária devem ser tratados em um contexto histórico-metodológico único.

De acordo com os mesmos autores, o processo de criação artística, em função de suas peculiaridades, está inserido, de modo particular, na teoria geral do conhecimento propagada pelo materialismo dialético. Este se baseia nas articulações entre o fenômeno e essência, vistos como distintos momentos produzidos pela realidade objetiva e não pela consciência humana. No entanto, é importante salientar que a realidade comporta graus distintos, que ocorrem mediante determinadas leis e se alteram de acordo com a mudança das circunstâncias. Nesse sentido, o principal objetivo da arte seria o de buscar um maior aprofundamento e a compreensão máxima, ultrapassando, portanto, a superfície dos fenômenos. De acordo com eles:

\footnotetext{
"A verdadeira arte [...] visa captar a vida na sua totalidade onicompreensiva. Quer dizer, ela, a verdadeira arte, aprofunda-se sempre na busca daqueles momentos mais essenciais que se acham ocultos sob a capa dos fenômenos; mas não representa esses momentos essenciais de maneira abstrata, fazendo abstração dos fenômenos e contrapondo-se àqueles, e sim apreende exatamente aquele processo dialético vital pelo qual a essência se transforma em fenômeno, se revela no fenômeno, fixando, também, aquele aspecto do mesmo processo segundo o qual o fenômeno manifesta, na sua
} 
mobilidade, a sua própria essência. [...] A verdadeira arte, portanto, fornece sempre um quadro de conjunto da vida humana, representando-a no seu movimento, na sua evolução e desenvolvimento" (Marx \& Engels apud Lukács, 1965, p. 29)

Portanto, o processo de desenvolvimento das obras literárias só pode ser compreendido como parte integrante de todo o processo histórico social. A essência dos artefatos literários, seu valor estético e a influência que estes exercem sobre todo o conjunto social fazem parte do modo como o homem elabora seu mundo a partir de sua própria consciência. Somente a partir da concepção materialista da história é que se pode apreender a gênese e o desenvolvimento da arte e da literatura, no decorrer do processo histórico.

Engels (1965), entretanto, reafirmou que a atividade espiritual humana pode dispor de certa autonomia nos campos da arte e da literatura, caracterizado por um relativo desenvolvimento espontâneo. Este processo de relativa autonomia do campo ideológico é explicável em função do processo de divisão do trabalho. Segundo o autor, embora os trabalhadores responsáveis por esta esfera de produção tenham a ilusão de pertencerem a um campo autônomo, estes estão submetidos, em última instância, às leis do desenvolvimento econômico. No entanto, a articulação entre os níveis infra e superestrutural não pode ser vista de modo esquemático, portanto, os fenômenos literários não podem ser tomados como objeto. Cada esfera produtiva caracteriza-se por um crescimento espontâneo, intermediado através do sujeito criador, que se articula imediatamente às suas elaborações anteriores e as desenvolve. Contudo, de acordo com o autor alemão, "a autonomia a que nos referimos é fundada objetivamente na essência mesma do desenvolvimento, na divisão social do trabalho" (Lukács, 1965, p. 16).

No entanto, Marx \& Engels apontaram que, no decorrer da história das ideologias, constatou-se uma ausência de equilíbrio entre os diversos níveis de desenvolvimento. No que se refere à literatura, Marx apontou que, em determinados contextos históricos, no qual ocorreu uma acentuada expansão artística, esta nem sempre se articulou ao crescimento da sociedade como um todo. Segundo os autores alemães acima citados:

\footnotetext{
"Na história da humanidade sob o comunismo primitivo e sob a divisão da sociedade em classes, a respeito do qual escreveram Marx e Engels, não é de maneira alguma necessário que a cada florescimento econômico e social corresponda infalivelmente um
} 
florescimento da literatura e da arte, da filosofia etc. [...] não é absolutamente necessário que uma sociedade mais evoluída socialmente possua uma literatura, uma arte, uma filosofia infalivelmente mais evoluída do que as de uma sociedade com nível inferior de progresso". (Marx \& Engels apud Lukács ,1965, p.17)

Portanto, os autores insistem no princípio da desigualdade do desenvolvimento, em determinadas ocasiões, no decorrer da história das ideologias. Segundo eles, tanto a filosofia francesa do século XVII como a alemã, no século XIX, nasceram em países que possuíam um relativo atraso econômico. No campo dos fenômenos literários, por exemplo, Marx constatou que alguns períodos de grande florescimento cultural, como a literatura romântica alemã do século XIX, dos quais seus principais autores foram Goethe e Schiller, ocorreram quando a Alemanha sequer era um Estado nacional. Sua admiração pelo escritor Honoré de Balzac relaciona-se à capacidade deste em retratar personagens que, sob o reinado de Louis Phillippe (1830-1848) ainda se encontravam em estado embrionário. Somente após a morte do autor, sob Napoleão III (1852-1870) é que estes tipos sociais completariam seu desenvolvimento (Lukács, 1965, p.32).

Seguindo as mesmas ideias, as manifestações de cunho ideológico poderiam conter ou anunciar elementos que estariam presentes de modo inconcluso na base material. Isto ocorreria, principalmente, em função da coexistência de fatores provenientes de um determinado modo de produção ainda estarem presentes em etapas de transição. A tarefa do materialismo histórico seria, portanto, apreender de que maneira o princípio do desenvolvimento desigual poderia se exprimir em diferentes campos do conhecimento humano em contextos históricos distintos. De acordo com Lukács, trata-se de "um problema histórico concreto, ao qual o marxismo só pode dar resposta à base de uma análise concreta da situação concreta" $(1965,18)$.

\section{2 "Duas Caras" e a defesa do modelo privado como estratégia de DISSEMINAÇÃO DO ENSINO SUPERIOR}

A telenovela "Duas Caras" foi produzida e transmitida pela Rede Globo de Televisão entre 1 de outubro de 2007 e 31 de maio de 2008, no horário das 21 horas. No total, teve 210 capítulos. Em média, estes tiveram a duração de 45 a 70 minutos, dependendo do dia de exibição. Era veiculada de segunda a sábado, no 
horário de maior audiência da emissora. Foi exibida a partir do dia 5 de novembro de 2007 também pela emissora portuguesa SIC. No ano de 2009, foi transmitida também no Paraguai através da emissora SNT Cerro Corá, no horário das 21 horas. No Brasil, sua audiência média foi de 42 pontos no IBOPE, que foi considerada pela emissora como insuficiente para o horário. No âmbito técnico, foi a primeira telenovela da Rede Globo completamente produzida no sistema HDTV $^{5}$, em alta definição, prenunciando a introdução da TV digital no sistema televisivo brasileiro ${ }^{6}$.

"Duas Caras" foi escrita por Aguinaldo Silva, com a ajuda de seis colaboradores. A direção-geral foi de Wolf Maya, com quatro diretores assistentes. No total, a equipe técnica foi composta de aproximadamente duzentas pessoas e em torno de cento e dez atores. ${ }^{7}$ Para a gravação da maior parte das cenas da trama, foi construída uma cidade cenográfica de 6.000 metros quadrados, que comportava os dois núcleos principais da novela: a comunidade Portelinha, inspirada na favela Rio das Pedras e os moradores da Barra da Tijuca. O custo total do cenário foi orçado em três milhões de reais. ${ }^{8}$ Além disso, foram gravadas cenas nos estados do Rio Grande do Sul e de Santa Catarina, Pernambuco, São Paulo e grande parte na cidade do Rio de Janeiro. Na primeira parte da história, também foram produzidas cenas em Paris, na França.

A telenovela possuía predominantemente dois núcleos principais, ambos ambientados na cidade do Rio de Janeiro: $O$ primeiro refere-se à comunidade favelada da Portelinha, liderada pelo líder comunitário Juvenal Antena e seu afilhado. O segundo é composto pelos novos-ricos da Barra da Tijuca, cuja principal personagem é Branca, proprietária da Universidade Pessoa de Moraes. O argumento central da trama gira em torno do personagem Adalberto Rangel, um nordestino pobre que consegue enriquecer através da execução bemsucedida de um estelionato. A partir disso, este foge para o Rio de Janeiro, realiza uma operação plástica e transforma-se em um empresário bem-sucedido, adotando o nome de Marcone Ferraço.

\footnotetext{
${ }^{5}$ Trata-se do sistema High Definition Television, no qual ocorre uma priorização da nitidez e qualidade da imagem em detrimento da quantidade de canais a serem transmitidos. Fonte: http://pt.wikipedia.org/wiki/Televis\%C3\%A3o digital\#HDTV, acessado em 14/03/2010. ${ }_{7}^{6} \mathrm{http}: / /$ www.oplanetatv.com.br/pag entrevistas.php?id=10, acessado em 14/03/2010.

7 Fonte: http://duascaras.globo.com/Novela/Duascaras/Personagens/0,9178,00.html, acessado em 12/03/2010.

8 Fonte: http://exclusivo.terra.com.br/interna/0,,Ol1781437-El9058,00.html, acessado em 13/03/2010.
} 
Segundo o autor principal da trama, Aguinaldo Silva, a proposta desta era discutir o problema da favelização nas grandes cidades, buscando romper o estereótipo veiculado pelo senso comum de que nas comunidades pobres do Rio de Janeiro predominam os traficantes, bandidos e existem tiroteios diários. De acordo com Aguinaldo, seu objetivo é mostrar o grande contingente de trabalhadores que habitam estes locais. Além disso, foram contemplados também o fanatismo religioso, que suscitou inúmeras críticas por parte da comunidade evangélica, a homossexualidade, a dislexia, o racismo e o tráfico de mulheres. No entanto, a história foi alvo de inúmeras críticas pela imprensa e por setores da sociedade, em função da grande parcialidade com que alguns temas de cunho político foram abordados ${ }^{9}$.

Em entrevista à imprensa, Aguinaldo Silva afirmou que uma das propostas da telenovela era discutir o problema da educação no Brasil, considerado por ele "um problema social" ${ }^{10}$.Com este objetivo, foi criado um núcleo de personagens na trama ligados à Universidade Pessoa de Moraes, de propriedade de Branca Pessoa de Moraes. Embora esta instituição esteja relacionada ao núcleo rico da telenovela, os habitantes da Barra da Tijuca e da comunidade da Portelinha também estudam no mesmo local. Nesse sentido, percebe-se que um dos ideologemas ${ }^{11}$ presentes na história é a legitimação do modelo privado de ensino superior e a defesa da política governamental que vem sendo implementada nos últimos anos de expansão do acesso deste nível de ensino às classes mais pobres, sobretudo através do crescimento das universidades privadas. A instituição privada televisiva é retratada como exemplar, com excelente infraestrutura em um dos pontos nobres, atualmente habitado por segmentos da burguesia carioca: a Barra da Tijuca.

Inicialmente, a universidade televisiva era administrada exclusivamente pelo seu fundador, que morre logo no início da trama. A partir disso, sua viúva propõe a indicação da sua filha ao cargo de reitor, o que é questionado pelo conselho deliberativo da instituição. Este é composto majoritariamente pelos

9 Fonte: http://www.observatoriodaimprensa.com.br/artigos.asp?cod=469TVQ001, acessado em 14/03/2009.

${ }^{10}$ Fonte: http://www.alinegraziela.com.br/saiba-mais-detalhes-de-duas-caras/08/29/, acessado em $14 / 03 / 2009$.

${ }^{11} \mathrm{O}$ conceito de ideologema aqui utilizado é o de Fredric jamson, no qual este é considerado como "a menor unidade inteligível dos discursos coletivos essencialmente antagônicos das classes sociais "Ver: JAMESON, Fredric. O Inconsciente Político: a narrativa como ato socialmente simbólico. São Paulo: Editora Ática, 1981. 
professores da instituição, dos quais se destaca o personagem Heriberto, que também almeja a direção da Universidade. Desse modo, a personagem Branca viaja para Paris em busca de sua filha, com o objetivo de convencê-la a assumir os "negócios" da família. Nesta mesma viagem, Branca conhece um representante da esquerda revolucionária brasileira, que se exilou na França durante o período ditatorial e lá permaneceu trabalhando como professor.

É importante destacar que Francisco Macieira foi tipificado como um reformador educacional moderno, embora, do ponto de vista ideológico, seja um defensor do discurso neoliberal. É importante mencionar a legitimidade concedida pelo autor à nova burguesia dos serviços educacionais, pois no capítulo veiculado em 29/10/2007, Macieira diz a Branca que esta deve tomar à frente da direção da Universidade se ela deseja que "a sua Universidade se transforme em um caçaníquel, ao invés de uma instituição de ensino".

Diante da recusa de sua filha em assumir a reitoria da Universidade Pessoa de Moraes, Branca convida Macieira para o cargo, já que em função da sua falta de experiência e da ausência de qualificação necessária, ela não pode administrar sua instituição de ensino. Macieira, pelo contrário, é um professor respeitado no meio acadêmico. No entanto, este expressa suas posições políticas sobre a questão educacional, no mesmo capítulo acima citado:

\footnotetext{
"Macieira -Eu não sou mais aquele visionário que nos tempos da ditadura saiu da prisão para o exílio. Eu vivi tempo demais na Europa... E por isso, agora, eu tenho uma outra visão do mundo. Principalmente na área do ensino...

Branca - Eu posso saber qual é?

Macieira - Depois de tanto tempo trabalhando com políticas e programas de educação institucionais, eu confesso que me decepcionei com eles. Eu acho que o governo sozinho não tem condições de bancar a educação superior.

Branca - É, eu sei....Não teria dinheiro nem existiria boa-vontade...

Macieira - Por isso minhas ideias se baseiam fundamentalmente no fortalecimento do ensino privado...Educação é investimento! Se a gente conseguir enfiar isso na cabeça dos empresários, por certo eles vão achar ótimo para os negócios deles investir pesadamente no ensino...

Branca - E você acha que as suas ideias dariam um novo rumo à minha Universidade?

Macieira - Depende... Aí a gente vai estar tratando de uma estrutura tradicional, onde não se pode provocar quaisquer mudanças sem provocar grandes traumas...Mas você é a dona! Se você quer inovar, mudar, a questão é: até onde você deseja ir?

Branca - O mais longe possível... (...) Sabe o que é que eu pretendo? Transformar a minha Universidade na melhor de todas! Eu quero criar um padrão de educação e por excelência ser citada por todos... e a ser seguida por todos...eu quero ser dona de um estabelecimento de ensino que seja orgulho para todo o país..."

Macieira- Você não me parece uma pessoa sequiosa de vingança... Está mais para visionária!"
} 
Portanto, o personagem Macieira é portador do discurso de classe que contempla os interesses do Estado neoliberal, pois os governos não podem mais arcar com os custos da educação superior e, ao mesmo tempo, da burguesia do setor de serviços, que vem expandindo sua lucratividade através do 'empresariamento ${ }^{12}$ ' do ensino. Portanto, seu processo de conversão à ideologia neoliberal é bastante representativo, pois desmobiliza a luta por uma educação superior pública e gratuita, vista aqui como um modelo ultrapassado. Além disso, a menção que se estabelece no diálogo de que após viver vários anos na Europa, ele teria repensado a questão educacional, aponta para a atuação dos organismos internacionais e, sobretudo, a Declaração de Bolonha ${ }^{13}$, como mentores do novo modelo de ensino superior que vem sendo gestado pelo Estado brasileiro nos últimos. A concepção empresarial da educação como investimento, preconizada pela teoria do capital humano ${ }^{14}$, também é destacada. Nesse sentido, o modelo de privatização do ensino superior é reafirmado no capítulo transmitido no dia 01/11/2007:

\footnotetext{
"Branca - Aceita ou não aceita minha oferta de trabalho? Hum... Ele se esquiva. Macieira - Mas que mulher insistente. Ela ri.

Branca - Você também, Macieira? A minha filha acabou de me acusar disso, sabia? Macieira - Deve haver uma razão para isso, não é não?

Branca - Há, sim. Há. Eu sei muito bem o que eu quero. Eu não desisto enquanto não conseguir.

Macieira - Eu confesso que eu gosto disso.

Branca - Ainda mais agora que eu não paro de pensar na ideia de que o futuro da educação está no investimento da iniciativa privada. Que tal nos dois juntos levarmos essa ideia adiante? Hum?

Macieira - Dona Branca, antes a sua Universidade. Depois "nós conversamos".
}

A indicação de um reitor proposto pela dona do estabelecimento superior de ensino foi utilizada na telenovela como justificativa para defender as posições

\footnotetext{
${ }^{12}$ Trata-se de um conceito usado por Lúcia neves Wanderley, que se articula à expansão do ensino provado no Brasil nos últimos, reafirmando a ideia de educação como mercadoria. Ver : NEVES, Lúcia M.W. O Empresariamento da Educação. novos contornos do ensino superior no Brasil dos anos 1990. São Paulo: Xamã, 2002.

${ }_{13}$ A Declaração de Bolonha foi firmada em 1999 por um conjunto de ministros da educação europeus de 29 países e teve o objetivo de promover a uniformização do ensino superior europeu, a fim de assegurar a empregabilidade e a mobilidade dos seus cidadãos. Disponível em: http://www.aauab.pt/bolonha/declaracaobolonha.pdf.

${ }^{14} \mathrm{~A}$ teoria do capital humano, elaborada pelo Estado norte-americano no pós-guerra e disseminada através de seus organismos internacionais, propunha a idéia de que os países periféricos solucionariam seus problemas estruturais através de investimento no âmbito do capital humano. Para mais informações, ver FRIGOTTO, Gaudêncio. A Produtividade da Escola Improdutiva; um (re) exame das relações entre educação e estrutura econômico-social capitalista. 4⿳亠丷厂 edição. São Paulo: Cortez, 1993.
} 
encabeçadas pelo governador José Serra, que impôs uma reitora de sua confiança na Universidade de São Paulo. Portanto, a trama contemplou a ocupação da reitoria pelos estudantes desta instituição, em maio de 2007. Estes tiveram o apoio do Sindicato dos Trabalhadores da USP (Sintusp) e da grande maioria dos docentes da universidade, que decidiram entrar em greve, em retaliação ao processo de sucateamento pelo qual as instituições públicas de ensino vêm sendo submetidas pelos últimos governos.

A reação do movimento estudantil foi originada a partir da publicação de três decretos do governador do Estado de São Paulo, José Serra, que incidiram diretamente sobre a autonomia universitária, expandiram a contratação de servidores em regime de trabalho precário e alteraram a administração de algumas entidades, de cunho estratégico para a área educacional. Além disso, foram propostas várias reivindicações pelos alunos, tais como: eleições diretas para reitor, obras de infra-estrutura, contratação imediata de professores e funcionários, aumento do número de vagas para o alojamento estudantil, expansão das linhas de ônibus na Cidade Universitária, abertura de bandejões e liberdade de manifestação política ${ }^{15}$.

Diante da recusa do governo do Estado em ampliar as negociações com os estudantes, foi usada a repressão policial para conter os manifestantes. No entanto, após 50 dias de ocupação da reitoria, os estudantes, funcionários e professores conseguiram que grande parte das suas reivindicações fosse atendida, freando algumas medidas neoliberais que o governo desejava implantar $^{16}$. Diante de um contexto de refreamento da luta de classes, a ocupação da USP e, em sequencia, da Unicamp e da PUC-SP configuraram uma das mais importantes mobilizações em defesa da educação pública nos últimos anos.

A telenovela reproduziu o discurso veiculado pela grande imprensa ${ }^{17}$ na época em que os protestos nas universidades paulistas ocorreram, no qual os estudantes foram tipificados como "radicais", baderneiros e responsáveis pela depredação do patrimônio público. É importante destacar que a principal reivindicação do movimento estudantil paulista, que foi a defesa do modelo

\footnotetext{
15 Fonte: http://veja.abril.com.br/idade/exclusivo/perguntas respostas/crise usp/index.shtml, acessado em 15/03/2010.

16 Fonte: http://noticias.terra.com.br/brasil/interna/0,,Ol1663805-El306,00.html, acessado em 15/03/2010.

17 Fonte: http://g1.globo.com/Noticias/Vestibular/0,,MUL44233-5604-8455,00.html, acessado em 16/03/2010.
} 
público para o ensino superior, foi descontextualizada ao transferi-la para uma instituição empresarial de ensino. Nesta, seus alunos não possuem qualquer interesse em intervir na organização administrativa, pois na medida em que a educação é tratada como mercadoria, estes são clientes que estão adquirindo um produto no mercado de bens e serviços. De acordo com Priolli (2008), "Duas Caras" "apresenta como modelo de comportamento a obediência bovina, acrítica e despolitizada dos "bons alunos" da Universidade Pessoa de Moraes" 18.

A tipificação dos estudantes como agitadores, inconsequentes e manipulados pelos professores da instituição superior de ensino televisiva, contrários à indicação proposta pela dona da Universidade, auxiliou no processo de construção de um consenso social no qual a atitude do movimento estudantil foi vista de modo negativo. Na trama, eles incendeiam as instalações do campus e agridem os policiais chamados para conter a manifestação. Pode-se dizer, portanto, que o discurso televisivo conseguiu retirar das audiências o apoio às causas dos estudantes, principalmente em um contexto de ampla desmobilização social. De acordo com Priolli (2008), "um dirigente estudantil comentou na Unicamp que, depois da novela, ficou impossível convencer à minha mãe que a política estudantil não é aquela baderna apresentada" ${ }^{19}$.

A legitimação da classe empresarial e, consequentemente, da propriedade privada é abordada no confronto entre a dona da Universidade e o principal representante do movimento estudantil na novela. Este é retratado através do personagem Rudolph Stenzel, um jovem negro adotado por uma família estrangeira da classe média alta, que possui um caráter ambíguo e pouco aplicado aos estudos. Segundo o site da trama no portal Globo.com, ele é "o aluno-problema", reforçando o estereótipo negativo dos estudantes engajados. $\mathrm{O}$ contraponto ideológico entre os dois personagens é ressaltado no capítulo transmitido no dia 03/11/2007:

\footnotetext{
"Branca - (...) E quanto aos alunos....também vão para casa... Não fiquem nos barzinhos bolando a grande revolução! Entre uma cerveja e outra. E amanhã, nem que eu tenha que transformar esses corredores em sala de aula, é um dia comum!Porque a vida no campus continua.
}

\footnotetext{
18 Fonte: PRIOLLI, Gabriel. Duas Caras para um só discurso. In: http://www.observatoriodaimprensa.com.br/artigos.asp?cod=469TVQ001, $\quad$ acessado em 16/03/2010.

19 Ibidem.
} 
Rudolph - Hoje demos o nosso primeiro passo! Em toda luta o difícil é o começo! O homem faz a sua própria história! E não se escolhe sobre que circunstância, hem? E se souber que ela...se defronte diretamente! As mudanças, as condições objetivas na luta exigem novas estratégias. Muitas vezes é preciso recuar um passo, para avançar dois na hora certa! Branca chega na sala e encara o líder.Como dizia o nosso camarada Lênin...

Branca - Vamos parar de proselitismo, idiota! Lênin hoje não passa de uma múmia, toda empoeirada lá no Kremlin!

Rudolph - A senhora não pode falar desse jeito!

Branca - E você não deu passo nenhum para frente nem recuou! Você simplesmente caiu de bunda no chão meu filho! É isso mesmo, perdeu! Perdeu feio! E se tiver um ouço de hombridade, você tem que reconhecer isso! E agradeça a deus de eu não expulsá-lo da minha Universidade e responsabilizá-lo por toda essa baderna!

Rudolph - Se a senhora fizer isso, os estudantes entram em greve! Os estudantes se levantam. Tudo bem! Estarão assinando o recibo de burrice, estarão fazendo greve contra eles mesmos! E agora saiam da minha sala, por favor, vão embora!

Rudolph - Nós perdemos a batalha porque a repressão foi violenta! Mas as circunstâncias mudam, Dona Branca! A luta continua e no próximo nós seremos os vencedores".

O conteúdo ideológico implícito no subtexto da trama é, de acordo com o diálogo acima citado, é a de veicular uma visão negativa sobre os indivíduos ou movimentos sociais que ainda lutem por uma sociedade mais justa. A referência ao socialismo real e ao processo revolucionário é, portanto, vista como politicamente ultrapassada e negativa. Isto, inclusive, é reforçado pela adesão do personagem Macieira, um ex-participante das barricadas estudantis ocorridas em 1968, à repressão imposta aos estudantes pela dona da Universidade. É importante lembrar que esta discussão é aqui, em última instância, irrelevante, em função da natureza do modelo privado de ensino. Contudo, a proposta do autor e dos setores vinculados à emissora é a de convencer o público-alvo de que o modelo neoliberal é inevitável e, portanto, o mais adequado aos "novos tempos". É interessante mencionar que o autor promoveu o processo de "conversão" do personagem Rudolph à ideologia da classe empresarial ao final da trama, no qual ele menciona que o "radicalismo não leva a nada" (capítulo transmitido no dia 30/05/2008).

Entretanto, é importante destacar a natureza do conflito social intrínseca aos artefatos culturais e ideológicos, como foi apontado por Jameson (1981). A presença da categoria contradição é apontada no texto televisivo aqui analisado, pois apesar de hegemonicamente este defender o processo de privatização do ensino, não desconsidera a excelência do ensino ministrado nas universidades públicas, como se menciona a seguir no capítulo transmitido no dia 20/03/2008: 
"Ramona - Gente, calma! O que ele quis dizer é que esse daí se comporta como se ele estivesse em uma universidade publica, só que na verdade ele está em uma particular! Já que ele é tão contra o capital, ele deveria ter optado em ir para uma pública. Só que eu aposto que ele não deve ter conseguido passar para nenhuma, né? Salvo pelo gongo, hem Rudolph?"

Por outro lado, a defesa das universidades privadas, que vem sendo utilizadas nos últimos anos pelo Estado como estratégia fundamental no processo de expansão do número de matrículas no ensino superior, é reafirmada no capítulo veiculado no dia 21/12/2007. Neste, o modelo privado é legitimado por um núcleo de personagens que representam segmentos da nova burguesia carioca, indicando que as classes mais abastadas não são mais partidárias da educação superior pública e gratuita. Além da defesa dos princípios da racionalidade econômica, percebe-se a importância do curso superior como mecanismo de diferenciação social, conforme o diálogo abaixo:

\footnotetext{
"Maria Eva - Ah, mas valeu a pena! Foi sensacional! Hem, gente, não foi? O homem destruiu, arrasou, tô arrepiada até agora, imagine! Ah, não, tomara, que quando vocês forem para a Pessoa de Moraes, Francisco Macieira ainda seja o reitor!

Filho - E quem disse que eu vou para a universidade?

Maria Eva - A mesma pessoa que afirma, ela estala os dedos. Ei, mocinho! Que filha de Maria Eva Monteiro Duarte não pode ficar sem um diploma!

Filho - Ah, mas você mesma, não tem, né?

Maria Eva - Porque eu não tive oportunidade, meu filho! Isso é o que não falta para vocês, não é? Oportunidades, mordomias mil...

Filha - Eu vou querer ir para uma universidade pública!

Pai - E pegar trânsito, para quê, minha filha? Olha aqui, se a Pessoa de Moraes for uma universidade de excelência, como o reitor está prometendo...

Filha - Ah, eu não! Prefiro muito mais ir para uma universidade que é disputada, que é respeitada e que ainda por cima é de graça, né?

Maria Eva -E levar dez anos para se formar porque os professores vivem em greve!

Pai - E ainda arriscar cair um pedaço de parede na sua cabeça, por falta de manutenção, que é o que mais a gente vê por aí!

Mãe - Não ter acesso a equipamentos de última geração!

Pai - Exatamente!

Maria Eva - Bons livros etc e tal.. Ah, me poupe, hem, Amanda! Até parece que você não lê jornal!

Filho - Ih, já vi que essa conversa vai longe!"
}

Percebe-se, portanto, a tentativa do discurso televisivo de convencer as audiências de que o modelo privado do ensino superior é mais "eficiente" em relação a uma educação pública de qualidade. Esta, vista como ineficaz e retrógrada, deve, contudo, adaptar-se ao novo processo produtivo, justificando o processo de 'empresariamento' do ensino que vem sendo implantado pelo Estado brasileiro nas últimas décadas. Em função disso, busca-se desqualificar os setores da sociedade, como os docentes das instituições públicas de ensino que 
ainda lutam pela manutenção da escola pública e por salários mais dignos e, principalmente os trabalhadores das universidades privadas. Isto, inclusive, é apontado no capítulo transmitido no dia 22/05/2008, quando os professores da Universidade Pessoa de Moraes exigem o restabelecimento dos seus bônus de produtividade e o reitor responde que "por enquanto, isso está absolutamente fora de cogitação. Até porque, vocês são muito bem-remunerados”. Desconsidera-se, portanto, a realidade socioeconômica dos trabalhadores das instituições privadas de ensino país, que veêm sua força de trabalho ser explorada diariamente pelos empresários do setor de serviços.

Por outro lado, a administração iniciada pelo personagem Macieira prega a adoção dos critérios quantitativos de produtividade que vem sendo submetidos aos docentes e estudantes de pós-graduação pelas agências governamentais de fomento à pesquisa, como a Coordenação de Aperfeiçoamento de Pessoal de Nível Superior, segundo o mesmo capítulo acima citado, no qual aqui é reproduzido um diálogo entre o novo reitor a secretária da Universidade:

\footnotetext{
"Heloísa - O senhor quer saber o que os nossos professores publicaram nos últimos dez anos?

Macieira - É isso, mesmo, notas, textos, teses, papers, projetos de pesquisa, livros, absolutamente, tudo...Você não sabe que os professores, além de dar aulas, na sala, também publicam, faz parte do trabalho deles....

Heloísa - Para ser franca, eu não sabia, não, o antigo reitor, o professor João Pedro, nunca me falou sobre isso...

Macieira- É, você vai ter que se acostumar com a minha administração, ela é inteiramente diversa do antigo... do outro reitor...

Heloísa - Quanto à isso, não tem problema, eu tenho certeza de que nós vamos nos dar muito bem....Eu vou providenciar tudo o que o senhor pediu...

Macieira - Heloísa... Eu quero tudo isso amanhã sobre a minha mesa..

Heloísa - Sim, senhor. .É o seu prazo. Ah, Heloísa, não se esqueça de relacionar em que revistas nossos professores publicaram, se revistas pedagógicas, científicas, absolutamente tudo. Ela o olha com espanto. E com uma cópia de cada artigo".
}

Nesse sentido, a "modernização" proposta pelo reitor Macieira enfatiza a ideia de que os trabalhadores docentes são "ineficientes" e pouco produtivos, de acordo com a lógica de reprodução do capital. Esta também se estende às mudanças realizadas pelo personagem na Universidade, incentivando a expansão da educação-mercadoria, isto é, da busca de valorização do capital mediante a venda de serviços educacionais, que vem ocorrendo no setor público e privado, segundo o capítulo transmitido no dia 24/12/2007: 
"Macieira - Portanto, vamos direto ao assunto para não perdermos tempo....Eu o
convoquei aqui, assim como todos os outros chefes de departamento, porque o assunto pede urgência...

Heriberto - Sim, sim, o que se presume!

Macieira - Eu vou trabalhar no Natal na preparação de novos cursos, portanto,eu preciso ouvi-los, portanto terão que trabalhar...

Heriberto - No fim do ano?

Macieira - Exatamente como eu. Eu preciso que vocês se reúnam, tantas vezes quanto forem necessárias, nos próximos 7 dias e que me apresentem pelo menos 30 sugestões de novos cursos...

Heriberto - Trinta?

Macieira - Aquelas que forem bem avaliadas por mim merecerão créditos para futuros aumentos...

Heriberto - Nós não seremos aumentados coletivamente?

Macieira - Não. Não, não, a partir de agora, os aumentos na Faculdade Pessoa de Moraes serão dados de acordo com o mérito de cada um".

É importante compreender que o estímulo da educação-mercadoria também faz parte da política educacional que vem sendo implantada pelo Estado brasileiro nos últimos anos. Este, além de admitir a possibilidade de lucro para as empresas de ensino, criou mecanismos que financiam o novo empresariado do setor educacional, como é o caso do ProUni ${ }^{20}$. Soma-se, ainda, a pressão que os organismos internacionais vem exercendo sobre o Estado brasileiro para expandir o número de vagas no ensino superior como uma importante estratégia de alívio à pobreza. Em função disso, é importante que sejam criados mecanismos que permitam o acesso das classes mais pobres ao modelo privado de ensino superior, como é mencionado no capítulo do dia 28/12/2007:

\begin{abstract}
"Macieira - Ah, gente , desculpe... Dona Branca, desculpe o atraso, mas é que eu estava analisando um projeto que quero apresentar para vocês. Obrigada.

Branca - Eu acho bom você começar logo, estão todos aflitos para ouvir o que você tem a dizer...

Macieira - Vamos direto ao assunto, trata-se da criação do sistema de concessão de bolsas de estudo para alunos em áreas carentes. Eles não terão que pagar nenhuma taxa de inscrição. Os primeiros classificados, É claro, terão preferência, terão bolsa integral. Os outros, por ordem de classificação e de carência, e de poder aquisitivo, terão bolsas parciais.

Heriberto - Espero que não seja preciso diminuir o salário dos professores para custear as despesas...

Macieira - Mas é claro que não, Heriberto! Os cursos serão financiados pela iniciativa privada, que inclusive, vai poder abater a despesa no imposto de renda. Todos concordam. E para terminar, eu gostaria de informar ao corpo docente que todos os professores, inclusive eu, darão cursos livres na Universidade".
\end{abstract}

${ }^{20}$ O Programa Universidade para Todos (ProUni). tem o objetivo de conceder bolsas de estudos integrais ou parciais para estudantes dos cursos de graduação ou de formação específicas, em escolas privadas do ensino superior, com ou sem fins lucrativos. Foi instituído em 2005. Fonte: http://prouni-inscricao.mec.gov.br/PROUNI/Oprograma.shtm, acessado em 10/12/20010. 
A defesa ideológica do ensino superior privado como um importante mecanismo de ascensão social pelas classes trabalhadoras, preconizando a associação incondicional entre educação e desenvolvimento econômico, também é aqui ressaltada. Trata-se de um mecanismo utilizado na trama para legitimar o acesso das classes mais pobres ao modelo privado de ensino, na medida em que este "naturalmente" os integrará ao mercado de trabalho. Isto é abordado no capítulo veiculado no dia 01/01/2008, quando o personagem Macieira vai à comunidade carente da Portelinha, divulgar o processo seletivo da sua Universidade:

\begin{abstract}
"Macieira - (...) E já que eu estou aqui e vocês aí, eu quero aproveitar a oportunidade e divulgar um projeto da Universidade que vai garantir a muitos de vocês da Portelinha um futuro melhor! Garantir oportunidade de trabalho é investir em educação. Por isso, nós vamos realizar um provão, para selecionar aqueles mais aptos ou para aqueles que há muito deixaram de estudar. Evidentemente, os melhores colocados receberão bolsas e os outros pagarão quase nada. Mais detalhes, eu vou revelar posteriormente, muito obrigado".
\end{abstract}

Por outro lado, a incondicional adesão dos habitantes da Portelinha ao processo seletivo da Universidade Pessoa de Moraes reforça a legitimidade do projeto de 'empresariamento' do ensino superior. Nesse sentido, o personagem Evilásio é o mais representativo do consenso social que vem sendo construído pelas diferentes frações burguesas para as classes populares, no qual a teoria do capital humano é um de seus principais pilares. A ideia de que os setores mais pobres através da escolarização conseguiriam automaticamente postos de trabalho mais qualificados e, consequentemente, ascendem na escala social é também considerado no capítulo do dia 22/02/2008:

"Júlia - Você vai fazer supletivo?

Evilásio - Eu já saquei uma coisa, branquinha, por mais que eu me esforce no trabalho, eu não posso contar somente com a minha intuição. Não, ta certo que o Narciso às vezes me da uns livros para ler,mas às vezes o pessoal fala umas coisa que eu fico boiando geral, sabe? Não, eu tenho que estudar. Eu tenho que abrir minha cabeça para pensar, sabe?

Júlia - Nossa, você não sabe como que eu fico feliz.... Você não sabe como que eu fico feliz.de ouvir isso....Você pode contar comigo, eu te dou a maior força e te digo mais... acho que supletivo só, não! Você tem que fazer faculdade! É verdade! Eu te ajudo, eu estudo com você...

Evilásio - Você acha que dá?

Júlia - Claro, eu posso até pedir uma bolsa para minha tia Branca para você estudar lá na Pessoa de Moraes. Aí, imagina, Evilásio, você fazendo faculdade, você se formando! Você vai fazer vestibular para que?

Evilásio - Peraí, Branquinha, não delira, eu ainda nem fiz o supletivo, já ta assim...Se eu fosse fazer, eu poderia fazer para Sociologia, Ciências Políticas..." 
Além disso, a trama reforçou a utilização do ensino a distância como uma importante via de acesso da classe trabalhadora ao ensino superior. Esta questão foi abordada de modo acrítico, sem discutir as implicações e os interesses econômicos articulados ao discurso tecnofílico atualmente em curso. Além disso, concedeu legitimidade à estratégia que vem sendo promovida pelo Estado e pelo empresariado em utilizar a modalidade a distância no processo de "massificação" deste nível de ensino. Estes ideologemas foram expressos no capítulo veiculado no dia 25/01/2008, no qual o estímulo à ampla certificação através do ensino a distância foi contemplado:

\footnotetext{
"Benoliel - Torce por mim, pai, o Provão é hoje!

Pai - Vou torcer, filhão! Vou torcer! E você vai passar, não tenho dúvida nenhuma disso! Vai passar! Mas agora, me explica uma coisa, o serviço, não vai coincidir o negócio de horário?

Benoliel - A faculdade tem um esquema para quem trabalha. É o seguinte: se eu passar, eu estudo pela Internet e só vou lá uma vez por semana, entendeu?

Pai -Tu ainda vai ser alguém, Benoliel, tu ainda vai ser.... Eu tenho certeza disso. Vou ter o prazer de ter ver entrando por essa porta segurando um diploma de administrador de empresas na mão!"
}

A defesa da neoliberalização como a alternativa mais eficaz na melhoria do quadro educacional do país é novamente reafirmada no discurso proferido pela dona da instituição de ensino televisiva. Este ressalta a importância da iniciativa privada como condutora do projeto político-pedagógico que vem sendo disseminado em parceria com o Estado brasileiro nos últimos anos, e a ineficiência deste como gestor neste âmbito, foram expressos no capítulo transmitido no dia 11/01/2008:

\begin{abstract}
"Branca- Bom, senhores e senhoras, em primeiro lugar eu quero dizer que não é toda hora nesse país que se vê um cheque de cinco milhões de reais doados á educação! Para ser sincera, é a primeira vez que eu vejo um destes! Ë verdade! Agora acho também que está mais que na hora do empresariado investir pesado em educação! Garantir em benefício próprio que profissionais altamente especializados entrem no mercado todos os anos! Eu tenho certeza que com isso, a educação não estaria no estado tão deplorável que está! Nem vou comentar o ranking vergonhoso que foi publicado no final do ano passado nos jornais quanto ao nosso país como lanterninha em relação ao ensino."
\end{abstract}

Percebe-se, portanto, a veiculação do projeto político-pedagógico da burguesia industrial que vem sendo posto em prática pelo Estado brasileiro nos últimos anos, no qual o empresariado busca conformar a classe trabalhadora aos 
anseios do capital. Além da educação ser considerada um importante vetor de desenvolvimento econômico, esta é também vista como fundamental para a melhoria da capacitação profissional dos indivíduos. Trata-se, portanto, da disseminação de uma proposta pedagógica utilitária e pragmática, que elimina o caráter emancipatório do processo educacional. Mediante a utilização do discurso da "empregabilidade", a classe empresarial busca disseminar um modelo de educação que ajuste os trabalhadores às novas exigências do processo produtivo.

\section{Referências bibliográficas}

BIONDI, Antonio; CHARÃO, Cristina. Terra de Gigantes. Revista Adusp, São Paulo, 2008. Disponível em: http://www.adusp.org.br/revista/42/r42a01.pdf, acessado em 20/10/2009.

BOLAÑO, César R.S. Mercado Brasileiro de televisão, 40 anos depois. In: BRITTOS, V.C.; BOLAÑO, C.R. S.(orgs.). Rede Globo: 40 anos de poder e hegemonia. São Paulo: Paulus, 2005. págs.1-34.

BOURDIEU, Pierre. O Poder Simbólico. 3르 edição. Rio de Janeiro: Bertrand Brasil, 2003.

CASTRO, Cosette. Globo e educação: um casamento que deu certo. In: BRITTOS, V.C.; BOLAÑO, C.R. S.(orgs.). Rede Globo: 40 anos de poder e hegemonia. São Paulo: Paulus, 2005. págs.243-263.

FRIGOTTO, Gaudêncio. A Produtividade da Escola Improdutiva; um (re) exame das relações entre educação e estrutura econômico-social capitalista. $4^{\mathrm{a}}$ edição. São Paulo: Cortez, 1993.

LUKÁCS, Georg. Ensaios sobre Literatura. Rio de Janeiro: Editora Civilização Brasileira, 1965.

Editeur, 1975.

. Marx e Engels historiens de la litterature. Paris: L'Arche

GENTILLI, Pablo. A Falsificação do Consenso: simulacro e imposição na reforma educacional do neoliberalismo. 2ª edição. Petrópolis, RJ: Editora Vozes, 1998.

JAMESON, Fredric. O Inconsciente Político: a narrativa como ato socialmente simbólico. São Paulo: Editora Ática, 1981.

edição. São Paulo: Editora Ática, 2000.

Pós-modernismo: a lógica cultural do capitalismo tardio. $2^{\text {a }}$

NEVES, Lúcia M.W. O Empresariamento da Educação. novos contornos do ensino superior no Brasil dos anos 1990. São Paulo: Xamã, 2002. 